\title{
A Puff-by-Puff Delivery Model for Cigarettes*
}

\author{
by \\ P. Chen and R.W. Dwyer
}

Philip Morris Research Center, Richmond, VA 23261, USA

\section{SUMMARY}

Materials generated by combustion and pyrolysis in a lit cigarette move through the tobacco rod and filter sections in two phases, the particulate phase and the gas phase. Some particles are removed while moving through the rod and filter sections. The gas-phase materials include the vapor of many volatile compounds. While moving through the rod and filter sections, part of the vapor are removed by adsorption and condensation.

In this study, a puff-by-puff delivery model for cigarettes is developed to calculate "tar", water, and nicotine in smoke on a puff-by-puff basis. A number of parameters can be obtained by the best fit to the experimental results of some cigarettes with different filter lengths. The parameters include the materials generated at the coal for each puff, the particle and vapor removal constants for tobacco rods and filters. The parameters may be useful in understanding some characteristics of cigarette smoke. [Beitr. Tabakforsch. Int 20 (2002) 273-77]

\section{ZUSAMMENFASSUNG}

Substanzen, die während der Verbrennung und der Pyrolyse in einer brennenden Cigarette erzeugt werden, bewegen sich in zwei Phasen, der Partikelphase und der Gasphase, durch den Tabakstrang und die Filterteile. Einige Partikel werden während der Strömung durch den Tabakstrang und die Filterteile entfernt. Die Gasphase enthält Gase vieler flüchtiger Komponenten. Während der Strömung durch den Strang und die Filterteile wird ein Teil der Gase durch Adsorption und Kondensation entfernt. In dieser Untersuchung wird ein Modell entwickelt, das auf der Basis eines Zuges das nikotinfreie Trockenkondensat, Wasser und Nikotin im Rauch von Cigaretten ermittelt. Eine Anzahl von Parametern kann in sehr guter Übereinstimmung mit den experimentellen Ergebnissen einiger Cigaretten mit unterschiedlicher Filterlänge berechnet werden. Hierzu zählen die Substanzen, die bei jedem Zug im Ascheteil gebildet werden, sowie die Koeffizienten für die Entfernung von Partikeln und Gasen durch Tabakstrang und Filter. Diese Parameter können für das Verständnis einiger Besonderheiten des Cigarettenrauchs nützlich sein. [Beitr. Tabakforsch. Int 20 (2002) 273-77]

\section{RESUME}

Les matériaux générés par combustion et pyrolyse dans une cigarette allumée migrent à travers le boudin de tabac et le filtre en deux phases : phase particulaire et phase gazeuse. Quelques particules sont éliminés au cours de leur migration à travers le boudin et le filtre. La phase gazeuse comprend les gaz de nombreux composants volatils. Au cours de la migration à travers le boudin de tabac et le filtre, une partie des gaz est éliminée par adsorption et condensation. Dans cette étude, un modèle est développé pour calculer les rendements bouffée par bouffée en goudron, eau et nicotine de la fumée d' une cigarette. Un certain nombre de paramètres peuvent être calculés parce qu' ils sont en bonne concordance avec les résultats expérimentaux obtenus avec quelques cigarettes ayant différentes longueurs du filtre. Parmi ceux-ci figurent les matériaux générés dans la braise au cours de la bouffée et les constantes d' élimination de particules et de gaz dans le boudin de tabac et les filtres. Les paramètres pourraient aider à comprendre quelques caractéristiques de la fumée des cigarettes. [Beitr. Tabakforsch. Int 20 (2002) 273-77]

\section{INTRODUCTION}

A number of investigators have studied the delivery of selected smoke components as a function of puff number or cigarette butt length (1-7). It is known that materials generated by combustion and pyrolysis in a lit cigarette move through the rod and filter sections in two phases, the particulate phase and the gas phase. The residence time in the cigarette is short and the temperature drops nearly 
$400{ }^{\circ} \mathrm{C}$ in the first $1-\mathrm{cm}$ distance. Smoke components with higher boiling points quickly condensed to form very small liquid droplets (approximately 0.3 micron) or the particulate phase. Some particles are removed while moving through the rod and filter sections. Most of the volatile compounds remain in the gas phase. While moving through the rod and filter sections, part of the vapor will be condensed and adsorbed on the surface of tobacco shreds and filter fibers. Due to the shorter butt length for later puffs, fewer particles and less amount of vapor will be removed in the rod and filter sections. WALTZ and HÄUSERMANN (1) studied the effect of puff number on the composition of the smoke leaving a cigarette by considering the condensation of the smoke components and its physicochemical affinity for the particulate phase.

Based on the above observations and studies, the delivery prediction for cigarettes in this study includes the calculations of some components left in the smoke in both particulate and gaseous phases on a puff-by-puff basis. In order to understand the effects of some design parameters such as filter length on smoke-component removal in both particulate and gaseous phases, an analysis of the parameters reflecting the delivery of some smoke components used in the model is performed.

\section{MODEL DESCRIPTION}

The filtration efficiency for particulate materials can be considered to follow the logarithmic penetration law of particle filtration (6). However, some components in tobacco smoke such as water, total particulate material (TPM), and "tar" do not follow this law due to the volatile nature of the substances (8-10). By considering the contribution of the vapor-phase delivery, a two-phase component delivery equation can be written to include the lengths and dilutions for both tobacco rod and filter sections,

$$
\begin{aligned}
G= & V_{\mathrm{p}}\left(1-D_{\mathrm{F}}\right)\left\{Y_{\mathrm{p}} \exp \left(-k_{\mathrm{R}} L-k_{\mathrm{F}} L_{F}\right)\right. \\
& \left.+Y_{\mathrm{c}} \exp \left(-k_{\mathrm{CR}} L-k_{\mathrm{CF}} L_{\mathrm{F}}\right)\right\}
\end{aligned}
$$

where $L=L_{\mathrm{B} 1}\left(N_{\mathrm{p}}-j+1\right) / N_{\mathrm{p}}$, is the butt length, $L_{\mathrm{B} 1}$ is the rod length at the first puff, and $j$ is the puff number, $L_{\mathrm{F}}$ is the filter length, $V_{\mathrm{p}}$ is the puff volume, $D_{\mathrm{F}}$ is the total dilution factor, $G$ is the delivery of certain components for each puff, $Y_{\mathrm{p}}$ is the particulate portion, $Y_{\mathrm{c}}$ is the removable vapor portion of the component generated at the coal, $k_{\mathrm{R}}$ and $k_{\mathrm{F}}$ are the particle removal constants for rod and filter, and $k_{\mathrm{CR}}$ and $k_{\mathrm{CF}}$ are the vapor removal constants for rod and filter, respectively. The main mechanisms for the vapor removal include condensation and adsorption. The first term represents the component delivery in the particulate phase. The second term represents the component delivery in the vapor phase.

Considering the effect of dilution in the rod and filter sections, the total puff count of the cigarette can be determined by

$$
N_{\mathrm{p}}=\frac{L_{\mathrm{B} 1}}{L_{\mathrm{p}}+t_{\mathrm{s}} \mathrm{LBR}}
$$

where $L_{\mathrm{B} 1}$ is the rod length at the first puff, $L_{\mathrm{p}}$ is the burning length for each puff, $t_{\mathrm{s}}$ is the static burning interval, and LBR is the linear burn rate of the cigarette.

\section{Puff-by-puff delivery equations}

Equation [1] can be simplified by using the following definitions, i.e.,

$$
\begin{gathered}
A=V_{\mathrm{p}}\left(1-D_{\mathrm{F}}\right) Y_{\mathrm{p}} \exp \left(-k_{\mathrm{F}} L_{\mathrm{F}}\right) \\
B=V_{\mathrm{p}}\left(1-D_{\mathrm{F}}\right) Y_{\mathrm{c}} \exp \left(-k_{\mathrm{CF}} L_{\mathrm{F}}\right) \\
\frac{B}{A}=\frac{Y_{\mathrm{c}}}{Y_{\mathrm{p}}} \exp \left[-\left(k_{\mathrm{CF}}-k_{\mathrm{F}}\right) L_{\mathrm{F}}\right]
\end{gathered}
$$

Thus, for cigarettes without a filter, the ratio $B / A$ is the ratio of condensable material to particulate material generated at the coal. Due to the under-developed coal, less material is generated during the first puff; the material delivered during the first puff can be written as

first puff:

$$
G_{1}=A \eta \exp \left(-k_{\mathrm{R}} L_{\mathrm{B} 1}\right)+B \eta \exp \left(-k_{\mathrm{CR}} L_{\mathrm{B} 1}\right)
$$

where $\eta$ is the first puff correction factor for generated materials and assumed to have a value of 0.75 (11). The materials delivered during the later puffs can be written as follows,

2nd puff:

$$
\begin{aligned}
G_{2}= & A \exp \left(-\frac{k_{\mathrm{R}} L_{\mathrm{B} 1}\left(N_{\mathrm{p}}-1\right)}{N_{\mathrm{p}}}\right) \\
& +B \exp \left(-\frac{k_{\mathrm{CR}} L_{\mathrm{B} 1}\left(N_{\mathrm{p}}-1\right)}{N_{\mathrm{p}}}\right)
\end{aligned}
$$

3rd puff:

$$
\begin{aligned}
G_{3}= & A \exp \left(-\frac{k_{\mathrm{R}} L_{\mathrm{B} 1}\left(N_{\mathrm{p}}-2\right)}{N_{\mathrm{p}}}\right) \\
& +B \exp \left(-\frac{k_{\mathrm{CR}} L_{\mathrm{B} 1}\left(N_{\mathrm{p}}-2\right)}{N_{\mathrm{p}}}\right)
\end{aligned}
$$

last puff:

$$
G_{\mathrm{N}_{\mathrm{p}}}=A \exp \left(-\frac{k_{\mathrm{R}} L_{\mathrm{B} 1}}{N_{\mathrm{p}}}\right)+B \exp \left(-\frac{k_{\mathrm{CR}} L_{\mathrm{B} 1}}{N_{\mathrm{p}}}\right)
$$

For the total material delivery for all the puffs, let $z_{\mathrm{R}}=$ $\exp \left(-k_{\mathrm{R}} L_{\mathrm{B} 1}\right)$ and $z_{\mathrm{C}}=\exp \left(-k_{\mathrm{CR}} L_{\mathrm{B} 1}\right)$ therefore, $z_{\mathrm{C}}=z_{\mathrm{R}}^{k_{\mathrm{RR}} / k_{\mathrm{R}}}=z_{\mathrm{R}}^{\sigma}$,

$$
\begin{aligned}
\sum_{i=1}^{N_{\mathrm{p}}} G_{i}= & A_{\mathrm{z}_{\mathrm{R}}}\left[\eta+z_{\mathrm{R}}^{-1 / N_{\mathrm{p}}}+z_{\mathrm{R}}^{-2 / N_{\mathrm{p}}}+\ldots+z_{\mathrm{R}}^{-\left(N_{\mathrm{p}}-1\right) / N_{\mathrm{p}}}\right] \\
& +B_{\mathrm{z}_{\mathrm{C}}}\left[\eta+z_{\mathrm{C}}^{-1 / N_{\mathrm{p}}}+z_{\mathrm{C}}^{-2 / N_{\mathrm{p}}}+\ldots+z_{\mathrm{C}}^{-\left(N_{\mathrm{p}}-1\right) / N_{\mathrm{p}}}\right]
\end{aligned}
$$

For the material delivered during the first puff, 
Table 1. Characteristics of test cigarettes (8)

\begin{tabular}{lcc}
\hline Characteristics & EXP1 & $2 \mathrm{R} 1$ \\
\hline Length (cm) & 8.44 & 8.55 \\
Circumference (cm) & 2.50 & 2.50 \\
Average tobacco wt. (g) & 1.07 & 1.22 \\
Packing density (g/cm $\left.{ }^{3}\right)$ & 0.255 & 0.287 \\
Paper permeability (CORESTA) & 41 & 12 \\
Paper additive & Citrate & Phosphate \\
Cellulose acetate filter $\quad-$ & $1.6 / 57000 ;$ \\
$\quad$ (dpf/total denier) & - & $8.0 / 40000$ \\
Filter length (cm) & - & $0,0.5,1,2,3$ \\
Puff number per cigarette & 14 & 16 \\
\hline
\end{tabular}

$$
\begin{aligned}
\frac{G_{1}}{\sum_{i=1}^{N_{\mathrm{p}}} G_{i}}=\frac{A_{\mathrm{z}_{\mathrm{R}}} \eta+B_{\mathrm{z}_{\mathrm{C}}} \eta}{A_{\mathrm{z}_{\mathrm{R}}} \frac{z_{\mathrm{R}}^{-1}-\eta^{\prime}}{z_{\mathrm{R}}^{-1 / N_{\mathrm{p}}}-1}+B_{\mathrm{z}_{\mathrm{C}}} \frac{z_{\mathrm{C}}^{-1}-\eta_{\mathrm{c}}^{\prime}}{z_{\mathrm{C}}^{-1 / N_{\mathrm{p}}}-1}} \\
=\frac{z_{\mathrm{R}}^{-1 / N_{\mathrm{p}}}-\eta^{\prime}+\frac{B\left(z_{\mathrm{R}}^{-1 / N_{\mathrm{p}}}-1\right)}{A_{\mathrm{z}_{\mathrm{R}}}} z_{\mathrm{C}} \eta}{z_{\mathrm{R}}^{-1}-\eta^{\prime}+\frac{B\left(z_{\mathrm{R}}^{-1 / N_{\mathrm{p}}}-1\right)}{A_{\mathrm{z}_{\mathrm{R}}}} \frac{1-z_{\mathrm{C}} \eta_{\mathrm{c}}^{\prime}}{z_{\mathrm{C}}^{-1 / N_{\mathrm{p}}}-1}}
\end{aligned}
$$

where

$\eta^{\prime}=\eta+z_{\mathrm{R}}^{-1 / N_{\mathrm{p}}}(1-\eta)$ and $\eta_{\mathrm{c}}^{\prime}=\eta+z_{\mathrm{R}}^{-\sigma / N_{\mathrm{p}}}(1-\eta)$

For the later puffs,

$$
\frac{G_{j}}{\sum_{i=1}^{N_{\mathrm{p}}} G_{i}}=\frac{z_{\mathrm{R}}^{-j / N_{\mathrm{p}}}-z_{\mathrm{R}}^{-(j-1) / N_{\mathrm{p}}}+\frac{B\left(z_{\mathrm{R}}^{-1 / N_{\mathrm{p}}}-1\right)}{A_{\mathrm{z}_{\mathrm{R}}}} z_{\mathrm{C}}^{1-(j-1) / N_{\mathrm{p}}}}{z_{\mathrm{R}}^{-1}-\eta^{\prime}+\frac{B\left(z_{\mathrm{R}}^{-1 / N_{\mathrm{p}}}-1\right)}{A_{\mathrm{z}_{\mathrm{R}}}} \frac{1-z_{\mathrm{C}} \eta_{\mathrm{c}}^{\prime}}{z_{\mathrm{C}}^{-1 / N_{\mathrm{p}}}-1}}
$$

Usually, due to the temperature difference between the gas stream and the tobacco rod and filter during puffing, the vapor condensation happens much faster than particle removal, i.e. $z_{\mathrm{C}} \sim 0$ and $z_{\mathrm{C}}<<z_{\mathrm{R}}$, Equations [11] and [12] can be simplified. Therefore, for the first puff

$$
\begin{aligned}
\frac{G_{j}}{N_{\mathrm{p}}} \approx \frac{z_{\mathrm{R}}^{-1 / N_{\mathrm{p}}}-\eta^{\prime}+\frac{B\left(z_{\mathrm{R}}^{-1 / N_{\mathrm{p}}}-1\right)}{A_{\mathrm{z}_{\mathrm{R}}}} z_{\mathrm{C}} \eta}{\sum_{i=1}^{-1}-\eta^{\prime}+\frac{B\left(z_{\mathrm{R}}^{-1 / N_{\mathrm{p}}}-1\right)}{A_{\mathrm{z}_{\mathrm{R}}}\left(z_{\mathrm{C}}^{1-/ N_{\mathrm{p}}}-1\right)}} \\
=\frac{z_{\mathrm{R}}^{-1 / N_{\mathrm{p}}}-\eta^{\prime}+\frac{B\left(z_{\mathrm{R}}^{-1 / N_{\mathrm{p}}}-1\right)}{A_{\mathrm{z}_{\mathrm{R}}}} z_{\mathrm{R}}^{\sigma} \eta}{B\left(z_{\mathrm{R}}^{-1 / N_{\mathrm{p}}}-1\right)} \\
A_{\mathrm{z}_{\mathrm{R}}}\left(z_{\mathrm{R}}^{-\sigma / N_{\mathrm{p}}}-1\right)
\end{aligned}
$$

Table 2. Parameters obtained for test cigarette-rods

\begin{tabular}{l|c|c}
\hline Cigarette rod & EXP1 & 2R1 \\
\hline$A$ “tar" (mg/puff) & 5.072 & 5.197 \\
$A$ water (mg/puff) & 0.294 & 0.453 \\
$A$ nicotine (mg/puff) & 0.354 & 0.378 \\
$B$ "tar" (mg/puff) & 3.347 & 1.271 \\
$B$ water (mg/puff) & 3.267 & 4.074 \\
$B$ nicotine (mg/puff) & 0.898 & 0.395 \\
$k_{\mathrm{R}}\left(\mathrm{cm}^{-1}\right)$ & 0.1015 & 0.0911 \\
$k_{\mathrm{CR}}$ "tar" $\left(\mathrm{cm}^{-1}\right)$ & 0.860 & 0.967 \\
$k_{\mathrm{CR}}$ water $\left(\mathrm{cm}^{-1}\right)$ & 0.678 & 0.856 \\
$k_{\mathrm{CR}}$ nicotine $\left(\mathrm{cm}^{-1}\right)$ & 1.287 & 0.979 \\
\hline
\end{tabular}

And for the later puffs,

$$
\frac{G_{j}}{\sum_{i=1}^{N_{\mathrm{p}}} G_{i}} \approx \frac{z_{\mathrm{R}}^{-j / N_{\mathrm{p}}}-z_{\mathrm{R}}^{-(j-1) / N_{\mathrm{p}}}+\frac{B\left(z_{\mathrm{R}}^{-1 / N_{\mathrm{p}}}-1\right)}{A_{\mathrm{z}_{\mathrm{R}}}} z_{\mathrm{R}}^{\left[1-(j-1) / N_{\mathrm{p}}\right] \sigma}}{z_{\mathrm{R}}^{-1}-\eta^{\prime}+\frac{B\left(z_{\mathrm{R}}^{-1 / N_{\mathrm{p}}}-1\right)}{A_{\mathrm{z}_{\mathrm{R}}}\left(z_{\mathrm{R}}^{-\sigma / N_{\mathrm{p}}}-1\right)}}
$$

\section{RESULTS AND DISCUSSION}

The experimental data of HARTUNG (8) are used here to demonstrate how the delivery model works. The cigarettes tested were denoted as EXP1 and the Kentucky reference cigarette $2 \mathrm{R} 1$. The characteristics of the two test cigarettes are shown in Table 1 . These cigarettes were smoked puff-bypuff using the standard Federal Trade Commission (FTC) method. The puff-by-puff "tar", water, and nicotine delivery data for each cigarette were obtained. The butt lengths on the last puffs were measured at the end of the smoking tests.

The parameters derived as the best fit to the experimental data using nonlinear regression of Equations [13] and [14] are listed in Table 2 . The particle removal constants of the tobacco rods, $k_{\mathrm{R}}$, are assumed to be the same for "tar", water, and nicotine, since the particulate phase is actually a mixture of these materials. The vapor removal constants of the tobacco rods, $k_{\mathrm{CR}}$, obtained from Equations [13] and [14], are about ten times larger than the particle removal constants, $k_{\mathrm{R}}$. If we take a close look at the parameters derived for the two test tobacco rods, the particle removal constant of EXP1 rod is slightly higher than that of $2 \mathrm{R} 1 \mathrm{rod}$. The water particle generated at the coal of EXP1 rod is significantly lower while the "tar" vapor generated is significantly higher than 2R1 rod.

In order to study the behavior of filters on smoke component removal, HARTUNG (8) also used the filters with different lengths of $1 \mathrm{~cm}, 2 \mathrm{~cm}$, and $3 \mathrm{~cm}$ attached to the $2 \mathrm{R} 1 \mathrm{ciga}-$ rettes as shown in Figure 1. The plastic tubes were attached to make the tube plus filter length to be $3 \mathrm{~cm}$. The tipping paper extended $0.3 \mathrm{~cm}$ over the $2 \mathrm{R} 1 \mathrm{rod}$. The deniers of the cellulose acetate (CA) filters used in the experiments were $1.6 / 57,000$ and 8.0/40,000, respectively. Two duplicates of each cigarette configuration were smoked puff-by-puff using the standard FTC method. That is why the parameters shown in Figures 2 and 3 have two values. 


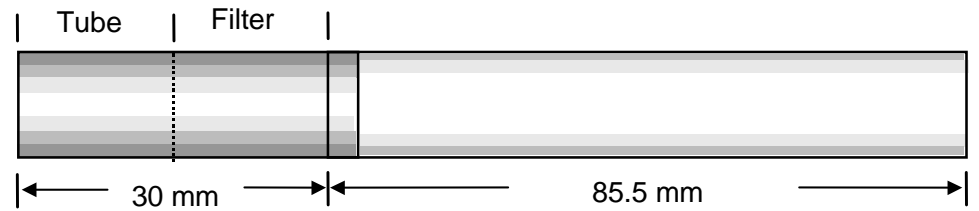

Figure 1. Set-up of filtered 2R1 cigarettes

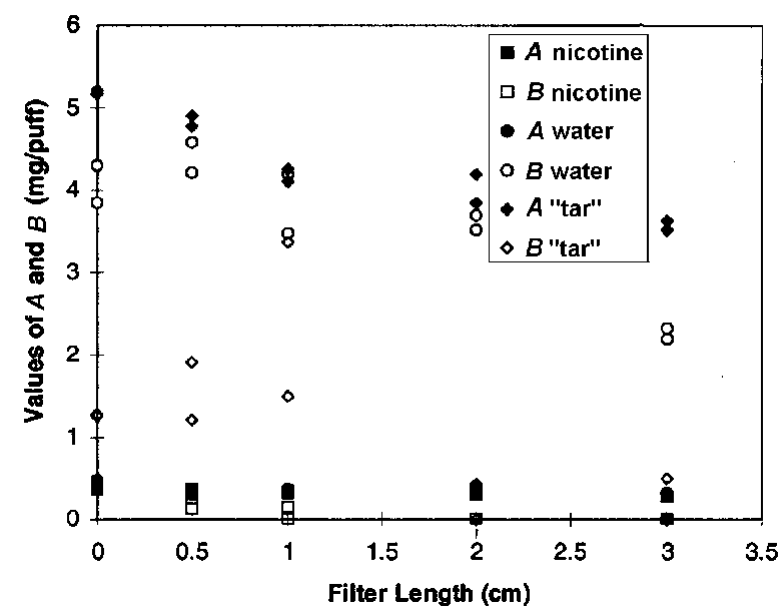

Figure 2. Parameter $\boldsymbol{A}$ and $\boldsymbol{B}$ vs. filter length (KY-2R1, CA filter 8.0/40,000)

Table 3. Smoke components removal constants for CA filters

\begin{tabular}{lcc}
\hline Filter (dpf/total denier) & $1.6 / 57,000$ & $8.0 / 40,000$ \\
\hline$k_{\mathrm{F}}\left(\mathrm{cm}^{-1}\right)$ & 0.4554 & 0.1356 \\
$k_{\mathrm{CF}}$ water $\left(\mathrm{cm}^{-1}\right)$ & 0.884 & 0.124 \\
$k_{\mathrm{CF}}$ nicotine $\left(\mathrm{cm}^{-1}\right)$ & 2.693 & 1.558 \\
\hline
\end{tabular}

By using Equations [13] and [14], the best-fit values of parameters $A$ and $B$ for filtered $2 \mathrm{R} 1$ tobacco rod can be obtained and are plotted against the filter length as shown in Figures 2 and 3. Comparing Figure 2 with Figure 3, it can be seen that the removal efficiency of the CA filter with the deniers of $1.6 / 57,000$ is higher than that of the filter with the deniers of 8.0/40,000. The particle removal constants, $k_{\mathrm{F}}$, can be derived for both CA filters by using Equation [3a]. The vapor removal constants, $k_{\mathrm{CF}}$, of nicotine and water can also be derived using Equation [3b], as shown in Table 3. However, the $k_{\mathrm{CF}}$ of water is in the same order of magnitude of $k_{\mathrm{F}}$.

As can be seen in both Figure 2 and Figure 3, the condensation/adsorption of the nicotine vapor might occur only in the first $1-\mathrm{cm}$ length of the filters, as the $B$ values for nicotine vapor become negligible when the filter length is greater than $1 \mathrm{~cm}$. The condensation/adsorption of the "tar" vapor behaves differently. The $B$ values for "tar" vapor increase with the filter length up to $1 \mathrm{~cm}$. But, when the filter length is greater than $1 \mathrm{~cm}$, the values of $B$ for "tar"

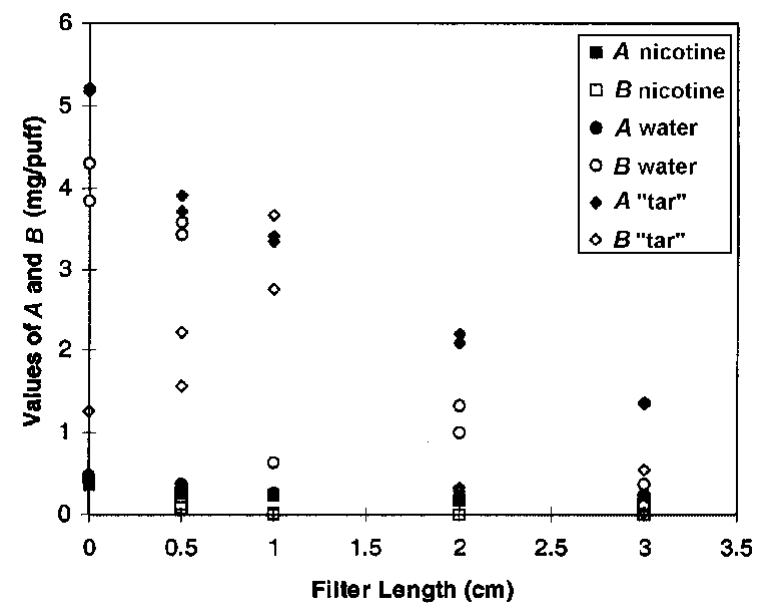

Figure 3. Parameters $\boldsymbol{A}$ and $\boldsymbol{B}$ vs. filter length (KY $2 \mathrm{R} 1, \mathrm{CA}$ filter 1.6/57,000)

vapor drops rapidly. The unusual behavior of "tar" vapor in the filters suggests the following phenomenon. If the filter length is less than $1 \mathrm{~cm}$, as water vapor contacts the filter by condensation or adsorption, certain amount of "tar" may evaporate or desorb from the filter. If the filter is longer than $1 \mathrm{~cm}$, "tar" vapor may then condense to or be adsorbed by the filter again. Therefore, the distillation-like processes of "tar" and water may occur in the filter.

\section{CONCLUSIONS}

A puff-by-puff delivery model for cigarettes is developed to calculate the materials left in the smoke on a puff-bypuff basis. The experimental data of HARTUNG (8) are used to obtain the parameters for EXP1 and 2R1 cigarettes with different filter lengths. The parameters obtained as the best fit to the experimental data may be useful in understanding some characteristics of the cigarette smoke in the tobacco rod and filter. For example, the vapor removal constants of the tobacco rods are about ten times as large as the particle removal constants. That is why condensation/adsorption are important mechanisms in the removal of the components in cigarette smoke.

The removal efficiency of the CA filter with the deniers of $1.6 / 55000$ is higher than that of the CA with the deniers of 8.0/40000. It is also noticed that, the condensation of "tar" vapor behaves quite differently in the filter. The behavior of "tar" vapor in the filters suggests the distillation-like process of "tar" and water vapor may occur in the filter. Therefore, more research work is needed for understanding the removal mechanisms of volatile smoke components in cigarettes. 


\section{REFERENCES}

1. Waltz, P. and M. Häusermann: Betrachtungen über die Veränderung des Tabakrauches in der Cigarette [Examination of cigarette smoke components]; Beitr. Tabakforsch. 3 (1965) 169-202.

2. Byckling von, E.: Untersuchung der Filterwirksamkeit des Tabakstranges bei Cigaretten verschiedener Härte in Abhängigkeit von der Abrauchlange [Investigation into the filter efficiency of the tobacco rod in cigarettes of differing density in dependence on the smoked length]; Beitr. Tabakforsch. 8 (1976) 382-391.

3. McRae, D.D.: A polydisperse aerosol model for cigarette smoke filtration; presented at the $35^{\text {th }}$ TCRC, Winston-Salem, NC, 1981.

4. Young, J.C., J.C. Robinson, and W.S. Rickert: A study of chemical deliveries as a function of cigarette butt length; Beitr. Tabakforsch. Int. 11 (1981) 87-95.

5. Yamamoto, T., U. Anzai, and T. Okada: Effect of cigarette circumference on weight loss during puffs and total delivery of tar and nicotine; Beitr. Tabakforsch. Int. 12 (1984) 259-269.

6. Baker, R.R. and D.P. Robinson: Tobacco combustion - The last ten years; Rec. Adv. Tob. Sci. 16 (1990), 3-71.
7. Baker, R.R. and D.P. Robinson: Semi-theoretical model for prediction of smoke deliveries; Proceedings of 1994 CORESTA Smoke \& Technology Meeting, Zimbabwe (1994) 63-72.

8. Hartung, H.A.: Personal communication, 1975.

9. Kassman, A.J.: Design of the filter systems; Rec. Adv. Tob. Sci. 10 (1984) 72-87.

10. Dwyer, R.W. and S.G. Abel: The efficiencies of cellulose acetate filters; Beitr. Tabakforsch. Int. 13 (1986) 243-257.

11. Dwyer, R.W. and P. Chen: Prediction of pressure drop and ventilation in a lit cigarette, Beitr. Tabakforsch. Int. 18 (1999) 205-211.

Address for correspondence

Peishi Chen

Philip MorrisUSA

Research Center

P.O. Box 26583

Richmond, Virginia 23261, USA

e-mail address peishi.p.chen@pmusa.com 